\title{
COVID-19 impact on waste management -business opportunity Emirate of Ajman - UAE
}

\author{
Khaled Mueen Alhosani ${ }^{*}$ and Pouria Liravi \\ University of Derby, Derby, United Kingdom
}

Received: 15 February 2021 / Received in final form: 21 March 2021 / Accepted: 22 March 2021

\begin{abstract}
The UAE's lifestyle has recently developed with increased population resulted in an increased waste from different resources (hazardous and non-hazardous). This has significantly got accumulated during the pandemic. Crisis management is one of the most important management practices that need careful modelling to include planning, framework practices, training, and reserved resources. Naturally, a complete plan for the expected crisis is ready for implementation when a crisis starts to reduce the crisis impacts. Moreover, those plans are to cover the periods before, during and after that crisis. Waste is a resource for many health, environmental, and social problems when not managed. Therefore, this paper aims to introduce elements needed in that combination of waste and crisis management and exploring the main critical elements that need to be contained and carefully studied to enhance modern waste management. The presumed management model examines the waste management practices prior to, during, and after the crisis. COVID-19 pandemics have severely affected all nations and critically disabled many services that governments are providing. Data collected for similar periods before and after the pandemic of the waste, including the amounts, practices, and associated outcomes. A concluded resultwas used to introduce a new framework model for the required initiatives of waste - crisis management. Results showed the importance of using the Waste - Business correlation for high-quality management. During the COVID-19 crises, a significant challenge is the massive quantity of regular waste that has become hazardous and required special treatment adding more cost and resulting in recyclable material reduction. The article has concluded that change in the dynamics of plastic, food, and biomedical waste generation during the same time has, however, stirred the woes of solid waste management. The non-hazardous waste was considered hazardous in many cases to minimize the chances of contamination. Inevitably, plastic has increased as personal protection and healthcare items increased with the reduced recycling process to avoid its adverse effect. Private businesses need to support Governmental efforts to deal with contingency. Materials Recovery Facilities (MRF) were getting less waste due to worries of contaminations and virus spreading. All these challenges and practices had a considerable effect on the Government waste associated budget.
\end{abstract}

\section{Introduction}

The United Arab Emirates (UAE) has recorded a rapid economic development boost in the past decade, making it the second-biggest economy in the Middle East region. Such development comes with increased solid waste production, mainly due to increased industrial activities as well as municipal solid waste (MSW) [1]. Among the seven Emirates, this threat is beyond real for the UAE's smallest Emirate in terms of land area, Ajman [2]. With just about a hundredsquare miles in size, the manufacturing sector $(40 \%)$ and real estate (15\%) remain the two

\footnotetext{
* e-mail: k.alhosani1@unimail.derby.ac.uk
}

largest contributors to the GDP [3]. With these and other sectors rapidly expanding, waste management has reached a critical juncture with the urgent need for revolutionary waste management interventions [4].

Waste is an inevitable product of society. It is a challenge to understand how to manage large quantities of different types of waste in a way that has benefits for society, the economy, and the environment. In this respect, Governments face a formidable challenge in finding solutions [5]. The world population is continuously increasing, reaching more than 7 billion, resulting in an increasing waste every day. More than $50 \%$ of that waste is not collected or treated or safely disposed of, and it is resulting in a rising waste associated crises and health issues. The Sustainable Development Goals (SDGs) cannot 


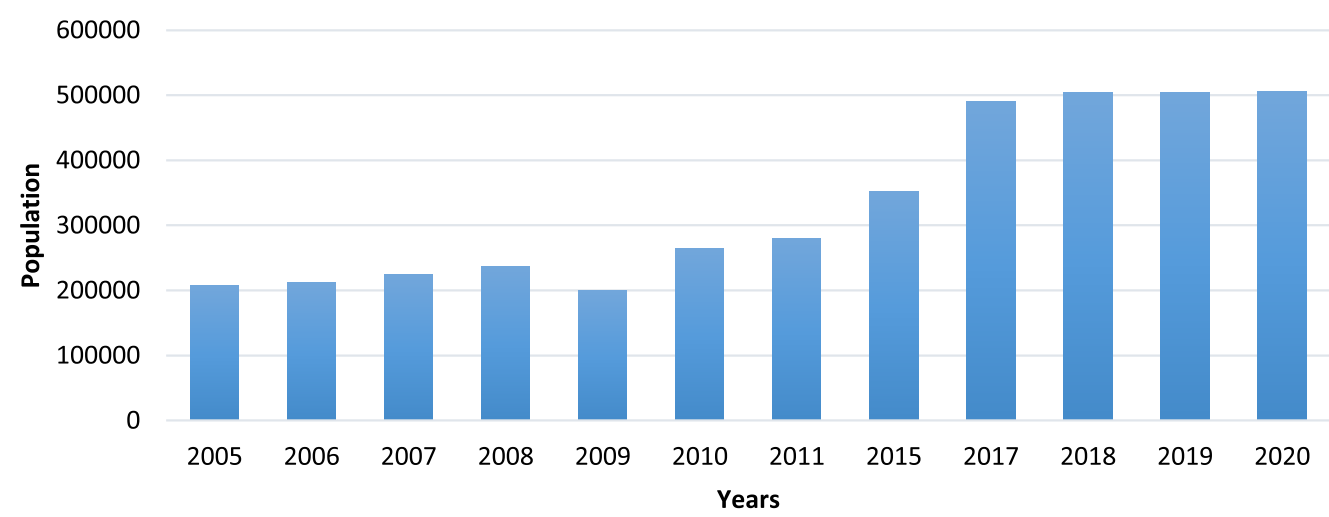

Fig. 1. Ajman Population from 2005 to 2020 [8].

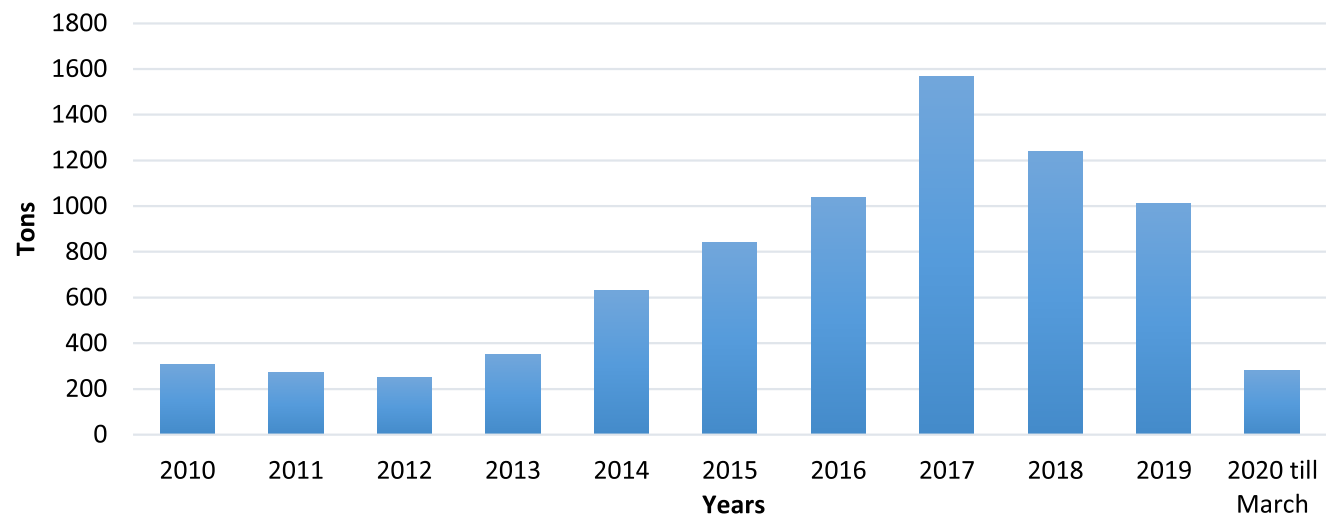

Fig. 2. The quantity of non-hazardous waste (Ajman - UAE) [8].

be met unless waste management is prioritized [6]. Waste management should be dealing with two main folds: First is the prevention and minimization and environmentally sound management of hazardous waste. The second is the policy measures for preventing and minimizing hazardous waste [7]. The Emirate of Ajman has experienced a population rise due to the improved wellbeing and increased construction and tourism projects in recent years, as in Figure 1 [8]. This increase has created a rise in the amount of municipal waste Figure $2[9]$ and a significant governmental challenge to manage this amount of waste. It is essential to anticipate strategies supporting achieving the UAE Governmental vision 2021 and the UAE Centennial 2071 to minimize the associated impacts of the ongoing growth in different waste streams Figure 3 [9].

Efficient waste management strategy includes practices to reduce harmful emissions and maintain the population's health and safety. In this respect, the Ajman Municipality and Planning Department considered projects to manage the integrated waste from the Emirate's everyday lifestyle. Ajman Government has recalled policies and practices to reduce the waste production rate and utilize the resulting waste through recycling, reusing and reduce principle with a great effort to raise public awareness [8].

The pandemic has drawn many of lessons highlighting the need for private business to support the Governmental efforts to deal with contingency and instance crises. A framework model for the business-focused interrelation between the Government's authorities and the business sectors must be put forward and carefully study a variety of critical and practical factors embedded from the extensive practical experience [10]. It must consist of effective policies, regulations, practices, correlations, education and trading rules [11]. This could open a wide range of business opportunities for the private business who can support the Government during a contingency.

Therefore, one of this paper's objectives is to review the waste management practices and achievements during the pandemic and what lessons were learned regarding crisis management. Comparisons are presented for different types of waste for the two periods. Preparations for several activities were recommended for future planning of a similar crisis. This article aims to identify factors that support the business - waste relationship capable of supporting the Governmental authorities' activities to achieve high performance in a crisis. This paper seeks to highlight the crisis management related to waste associated with the COVID-19 crisis and introduce a practical plan by exploring the main critical elements that need to be contained and carefully studied to enhance modern waste management. This is by taking into account the lessons learnt from practical activities carried out by the Ajman Municipality and Planning department. The results used to introduce a new framework model for the required 




Fig. 3. The growth of three waste streams in Ajman until the year 2040 (Ajman - UAE) [9].

initiatives of waste - crisis management. The framework will be a guide for any future pandemic.

\section{COVID-19 nature of crisis}

COVID-19 affected almost all countries worldwidein 2020 and will continue todo so in the upcoming years. Radical uncertainty was the situation that all countries' Governments were working on. Challenges raised regarding health, human tragedy, economic and social aspects were faced in complicated impact. It is now widely recognized that the pandemic triggered the most severe economic crisis since World War II. Many economies will not recover to their 2019 output levels until 2022 at the earliest [12]. Two types of waste were considered at risk and created challenges:household/domestic waste management (MSW) and waste generated through healthcare facilities. The followings are the main risks [13]:

- The increased amount of mixed waste, including infectious waste due to low levels of segregation at the source.

- The increased amount of plastic waste (due to lockdowns, suspension of reusable items in stores, etc.).

- Lack of incentivization/estimates on the amount of household hazardous waste being generated.

- Increased littering, illegal dumping and open burning.

- Suspension of recycling activities.

- Mixing of infectious Waste such as gloves, masks, tissues, and gauze with other wastes (exposure to transmission).

- Discontinued provision of formal/ informal waste management services.

- Increased negative impacts, especially to the informal sector (OSH, health risk, business opportunity loss, etc.).

- Improper MSWM service provided during regular times (vulnerability in collection services and landfill operation as well as $\mathrm{OSH})$.

- Lack of awareness regarding waste management.

- Reuse of disposed personal protective equipment (PPE).

- Lack of daily supply of PPEs to waste collectors.
Moreover, risks and challenges associated withwaste generated through healthcare facilities are [13]:

- The increased amount of infectious waste generation.

- Service interruptions of healthcare waste management services.

- Improper healthcare waste management treatment in place.

- Suspension of recycling activities.

- Insufficient capacity for waste treatment and disposal.

\section{Waste management for an expected crisis in Ajman before and during COVID-19}

With the continued spread of pandemics, including COVID-19 and the spread of their effects on human health, the need to treat and manage these wastes has increased, which includes:

- Waste from hospitals and medical centres.

- Waste of quarantine and medical isolation centres.

- Remnants of protective equipment (masks, gloves and protective clothing).

- Contaminated waste in homes through home quarantine.

As well as the health and environmental impacts of these wastes in the absence of proper management.

[14]:

As a result, the situation of waste in Ajman is as follows

- The quantities of waste collected from the quarantine and medical isolation centres during the month of April amounted to 70 tons.

- The competent authorities in each Emirate manage waste within the currently available medical waste incinerators and treatment systems.

- With the increase in the quantities, the need to expand the existing units appeared and the inability to accommodate additional quantities.

- It is impossible to carry out proper separation of the waste resulting from the quarantine centres and medical isolation centres, which requires treatment of all waste. 


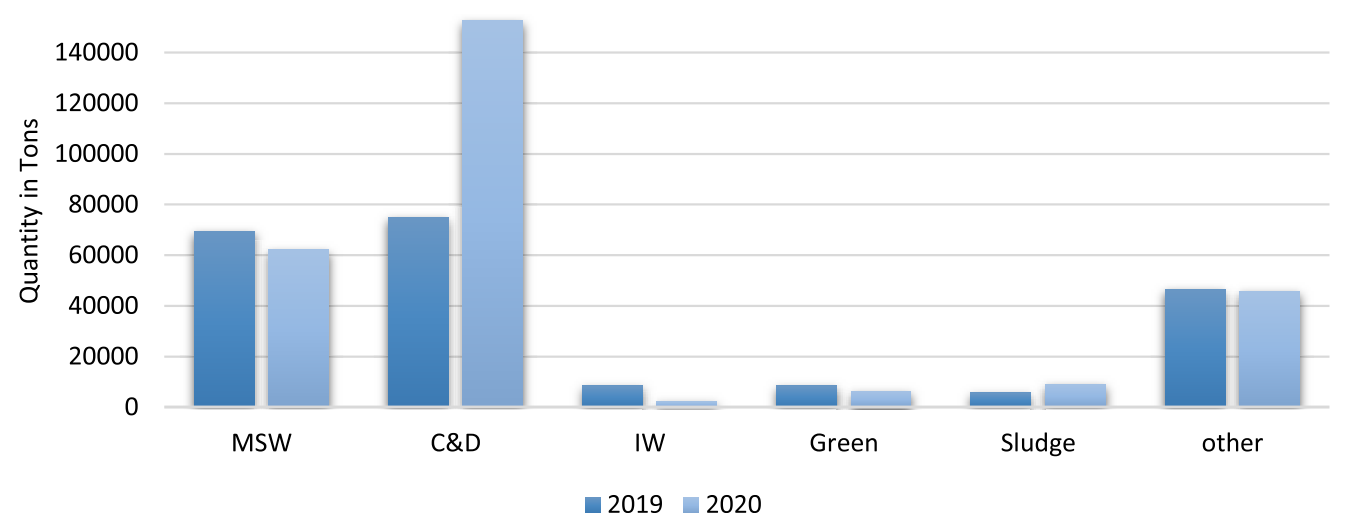

Fig. 4. Waste comparison 1st quarter (2019-2020) (Ajman - UAE) [15].

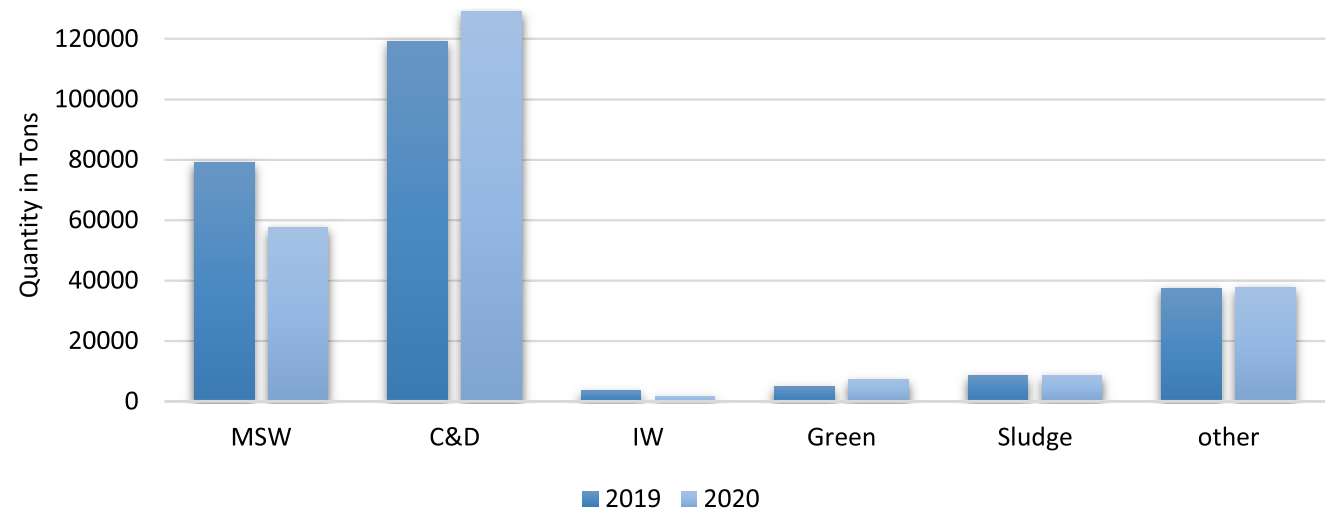

Fig. 5. Waste comparison 2nd quarter (2019-2020) (Ajman - UAE) [15].



Fig. 6. Waste comparison 2nd quarter (2019-2020) (Ajman - UAE) [15].

Moreover, a significant change has been noticed during the COVID-19 crisis, leading to many alterations and amendments to the waste collection, segregation, treatment and disposing of. These amendments' decisions were made to overcome the associated health and safety consequences. A large amount of the Municipal Solid Waste (MSW) was considered hazardous waste and sent to incineration due to contamination fears. Some left to be disposed to the landfill such as Construction and
Demolished (C\&D), Industrial Waste (IW), Green Waste (Green) and Sludge Waste (Sludge). However, much of these types were also considered Hazardous. A clear difference in the amount of waste recorded in the first quarters of 2020 when the crisis was started shows percentage of reductions around 20-25\% compared with similar periods in 2019. Figures 4-7 [15], show quantities of waste for three quarters of 2019 compared with 2020. Figure 8 present a total of MSW for four quarters. 


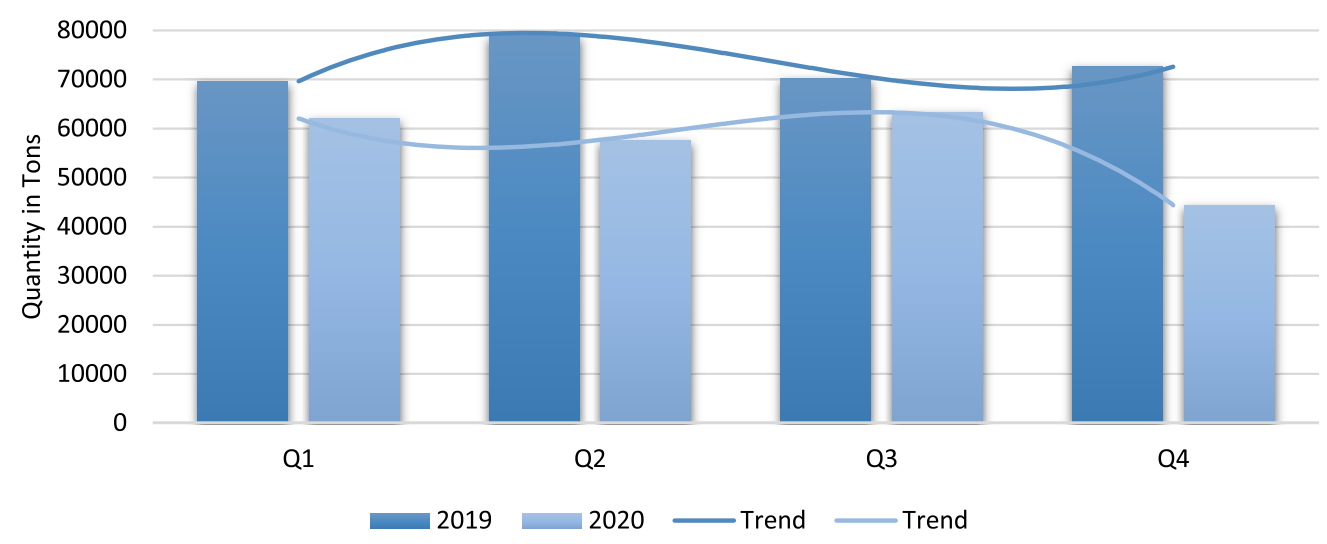

Fig. 7. Municipal solid waste comparison report almost $25 \%$ reduces as compare 2019 for four quarters (Ajman - UAE) [15].
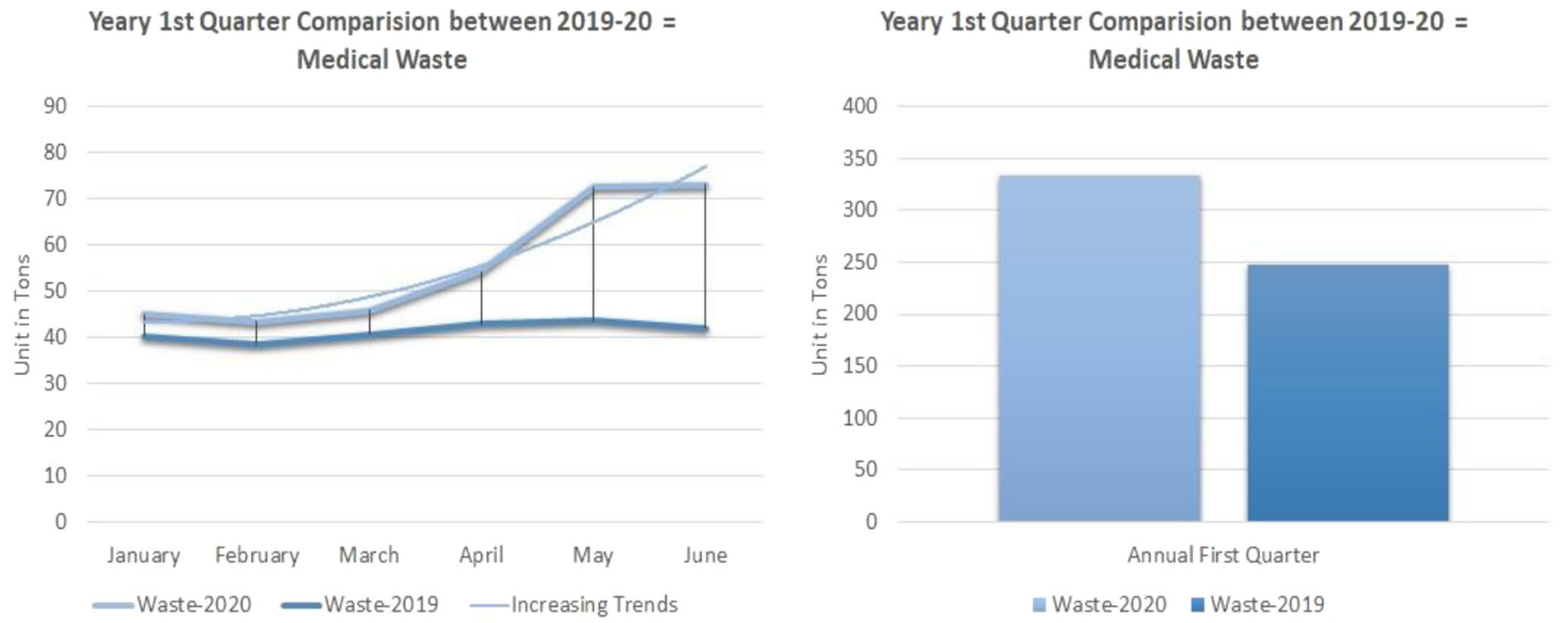

Fig. 8. Trend for the medical waste for the 1st quarter (2019-2020) (Ajman - UAE) [15].

Medical waste is also presented in Figure 8 and shows an increase of $20 \%$ compared with 2019 . This is an expected amount looking at the health crisis consequences. Figure 9 shows the amount of non-hazardous waste.

Moreover, Figure 10 presents the waste per capita and demonstrate a reduction of $20 \%$. Treated waste has been significantly reduced due to contamination, which leads to a decision to incinerate most non-hazardous waste, as presented in Figure 11.

\section{Crisis and contingency management}

It is how plans are put to deal with a disruptive and unexpected event that threatens the assets, society, organizations, economy, etc. Managing the crisis aims to avoid its consequences and eliminate that crisis. Three main steps are to be considered, planning to face the situation, contain the problem, and regain normal life activities after it happens. In order to attain successful management, it is essential first to discover the crisis and measure its dimensions. Three questions need to be answered in this respect; the first is when did it happen, second, when did we know about it and when it has developed? Moreover, it is essential to identify:

- Who is in favour or against?

- Who supported it?

- Who is benefiting?

- Who is affected?

- Who can face it?

- Who caused the crisis?

The crisis is a critical and decisive moment related to the administrative entity's fate afflicted by it and thus creating a severe difficulty for the decision-maker. It is a situation that results in environmental changes that generate crises and deviates from the usual framework and includes a degree of risk, threat, lack of time, and surprise. It is a turning point for a state of high tension that requires a decision that results in new situations, whether negative or positive, affecting the various entities involved. Many benefits can be gained from the crisis, such as: 
Yeary 1st Quarter Comparision between 2019-20 = Other Non- Hazardous Waste



Yeary 1st Quarter Comparision between 2019-20 = Other Non- Hazardous Waste



Fig. 9. Comparison of the amount of non-hazardous waste (2019-2020) (Ajman - UAE) [15].

Yeary 1st Quarter Comparision between 2019-20 = Waste Per Capita Generation



Yeary 1st Quarter Comparision between 2019-20 = Waste Per Capita Generation

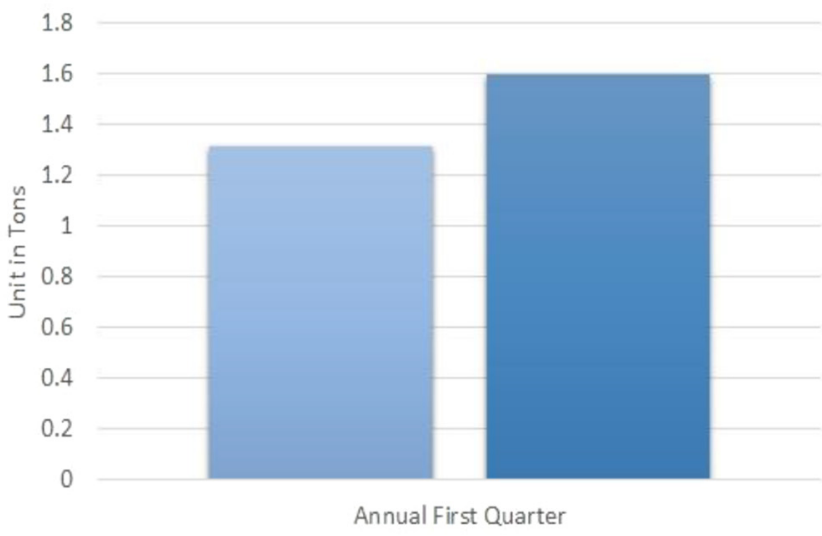

waste-2020 — Waste-2019

Fig. 10. Waste per capita generation 2019-2020 (Ajman - UAE) [15].

Yeary 1st Quarter Comparision between 2019-20 = Municipal Treated Waste

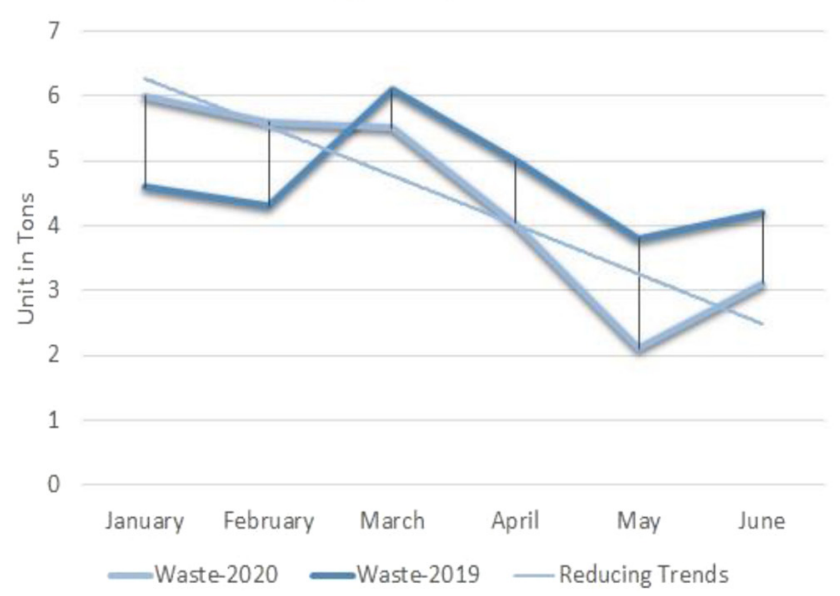

Yeary 1st Quarter Comparision between 2019-20 = Municipal Treated Waste

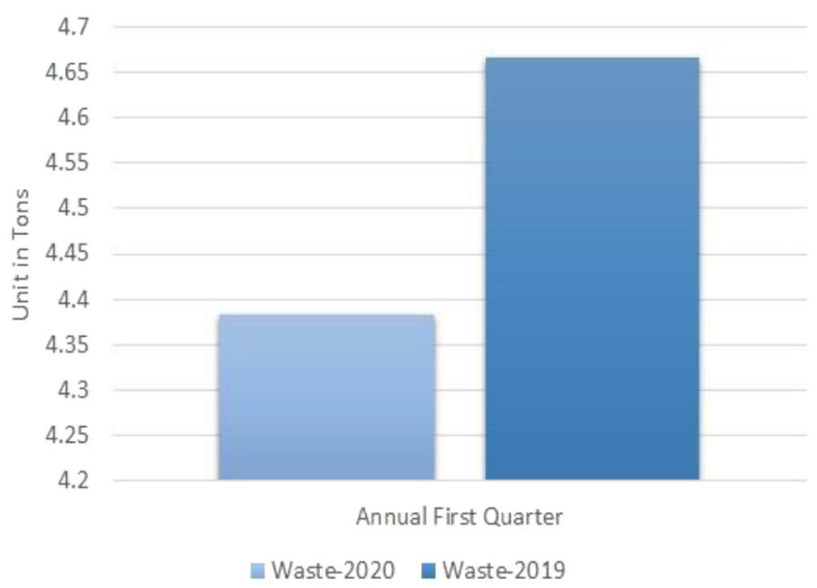

Fig. 11. Municipal treated waste 2019-2020 (Ajman - UAE) [15]. 


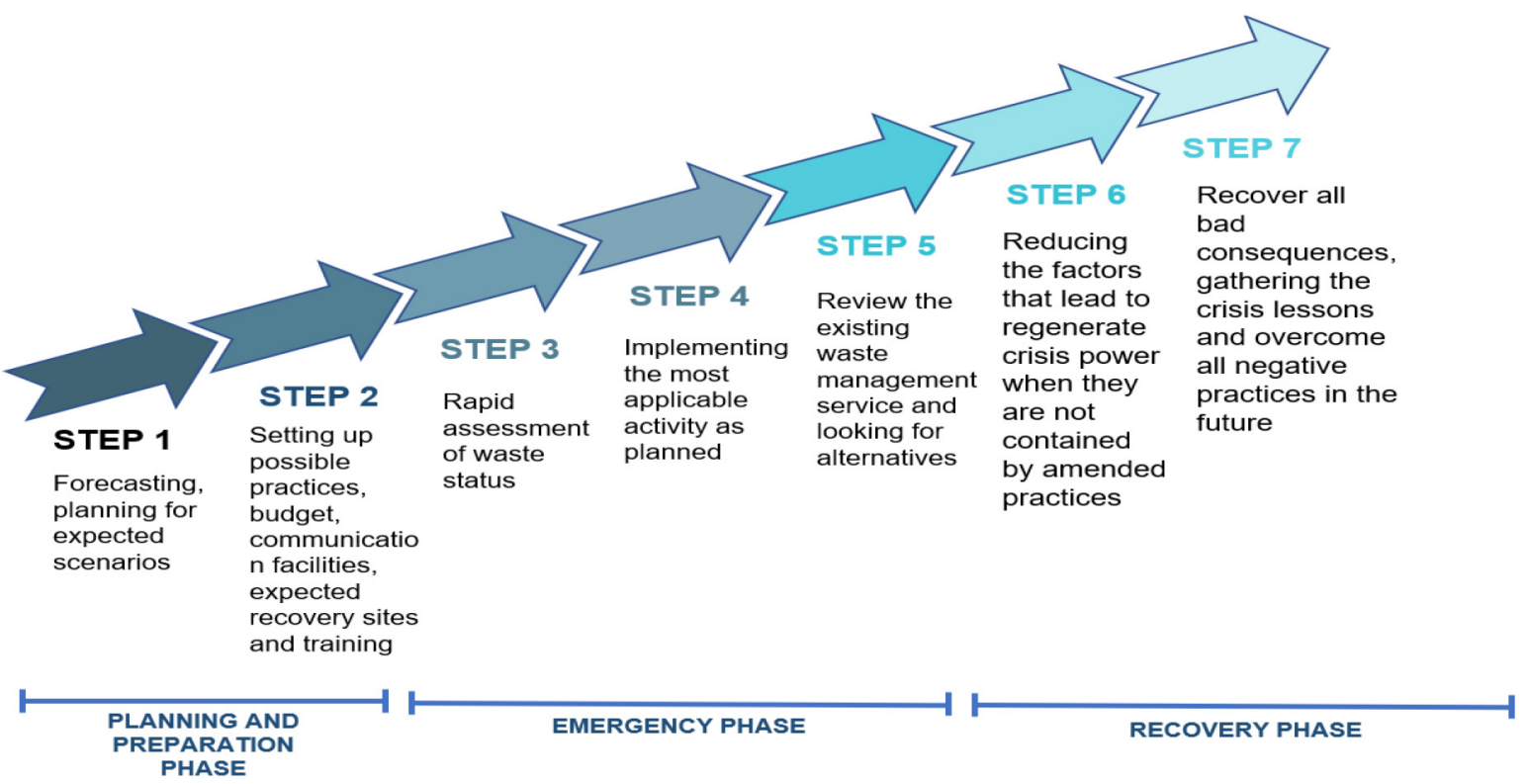

Fig. 12. summary of the contingency planning steps [Author Contribution].

- Show deficiencies (as the crisis shows a defect, while we think that everything is safe).

- Speeding up the change process (if the change is urgent and there is a slowdown in that, the crisis's emergence leads to accelerating change).

- Change the strategic path to achieve the goal.

- Provide the opportunity for the emergence of heroes. (A new generation commensurate with crisis management)

- Development of early warning systems.

- Achieve new competitive advantages. (As every crisis you pass through and succeed in solving it acquires new features).

- Raise the spirits when overcoming the crisis.

The crisis may take different stages like crisis generation, crisis development, and time that it will contain, containing the crisis and recovery.

\subsection{Critical considerations for making contingency plans}

Planning over a contingency takes many forms and steps. It has been practice by UNEP\&IGES (2020) [13] and the main suggested steps are:

- Consider both short term (emergency response plan) and long term (recovery plan) actions associated with implementing effective healthcare waste management.

- Carry out a quick survey and map sources of waste generation to identify changes in waste amounts/flows and increase the efficient use of resources.

- Maintain an existing waste management system to avoid other health risks due to the service interruptions of waste collection and treatment (Adjust collection service and treatment to manage an increased amount of waste).

- Outreach to increase awareness on sourcesegregation and properstorage/discharge, including double-layer bag use, coloured bag use, specific bag distribution, labelling, discharge place, etc.
- Protect lives and livelihoods both formaland informal sector workers who are involved in the waste management system (Occupational Safety and Health (OSH), social safeguards, etc.).

- Continue the practice of material reuse andrecycle as much as possible, and adjusting waste collection and transport systems to include waste.

- Examine existing treatment and disposaloptions for infectious waste management and promote the best available options to mitigate transmission risks.

- Permit temporary licensing, long-termstorage, intermunicipality collaboration, and transboundary arrangement for proper waste management in a timely manner, etc.

- Encourage multisectoral cooperation andinteraction at all levels.

- Ensure gender equality is taken into account, using gender-disaggregated data, women's participation in decision making and introducing health and safety measures.

From the points that have been discussed earlier and looking to the practical lessons learned from the activities from the Ajman Municipality and Planning Department Figure 12 shows the possible procedure for planning for waste associated contingency through three specific phases, planning and preparation phase, emergency phase and recovery phase.

\subsection{Achievements and creativity for waste management during the crisis}

The Coronavirus (COVID-19) pandemic has already had tremendous impacts on the waste sector worldwide and created a big challenge for the Emirate of Ajman. At first, while the pandemic was progressing and lockdowns imposed, the Ajman municipality's waste operators were 
trained to rapidly adapt their waste management systems and procedures to the situation using the latest and up to date practices and activities. To combat COVID-19 spread, training was organized to instruct and upskill the waste management staff and workers. The training sessions were conducted daily to review the emergency plans and enhance the up-to-date developments. Sessions were delivered to direct staff and workerson how to protectthemselves and others [16]. Special PPE's were provided during the collection and sterilization process and timely monitored staff and workers' COVID-19 testing results. Immediately started focuses on segregated waste from source specially COVID-19 quarantine areas. Moreover, the municipality has placed special waste containers at quarantine areas as well as timely sterilized. To ensure that the biowaste is transferred safely, specially trained individual staff are deployed to deal with quarantine areas waste to collect and a particular biowaste vehicle. Following these steps, the dedicated staff were deployed to incinerate quarantine areas waste. As a result of these safety procedures, no single staff was infected by the COVID-19 crisis. Another achievement is all waste management procedures is the staff and workers are well experienced to operate smooth waste management operations, and according to the national level sterilization.

Waste management has had several stages and challenges during the pandemic the Ajman Municipality had to tackle. For instance, during the lockdown, Ajman Municipality and Planning Department (AMPD) has to work through several steps and processes [14]:

- Increasing the number of workers to make social distances and the number of waste-collecting vehicles.

- AMPD has arranged for all needed resources to be available for sterilizing and cleaning.

- Government has been organized to sport the waste management process which helps a lot in managing the crisis properly and effectively.

- There was a challenge in keeping the worker safe to continue their tasks, so the AMPD provided the workers with all the safety clothes masks, cloves, one use dress, hand sanitizer and the sanitizing machine.

- The vehicle and workers accommodation were sterilized regularly in addition to weekly COVID-19 testing.

\subsection{Remarks for plans to be considered By Ajman municipality and planning department}

Waste Management plays a crucial role in controlling such kinds of pandemic which was never experienced before. From all practices and activities planned, leaned by training and gained from experience, an important issue is to form a specified committee to monitor and gather data from different countries on how well the waste management been tackled and what of their practices are worth following to achieve better performance. The aim is to gather and exchange practices and be aware that situations are diverse and dependent on the national and local constraints and available means. Moreover, continuous national sterilization must be performed to make sure the crisis will not return. It is also recommended that the authority carry out public awareness to explore the challenges and educate the public on the best practices that they shod contribute to overcoming any similar future crisis. Training sessions and courses must be a continuous activity for upskilling and training to have a team of skilled workers with plenty of experience to deal with similar crises. A review of the existing contingency plans should be maintained and periodically amended with up-to-date technologies.

From the above practices and creative achievements, suggestions andrecommendationsare drawn to put forward to improve contingency wastemanagement are:

- Adding an article in the manual on dealing with biological waste whenever a new edition is published.

- Including biological risks resulting from pandemics and infectious diseases, for example, the COVID-19 virus, in the biological contingency plan.

- Preparing an emergency plan for pandemics and infectious diseases that is always ready to implement to reduce pandemics' impact.

- Equipping special central treatment units for hazardous wastes or mobile incinerators for the proper disposal of those wastes produced by the establishments within the municipal solid waste treatment projects and ready to accommodate any quantities that may result from pandemics and infectious diseases.

\section{Waste management business challenges during COVID-19}

To ensure that the waste collection, transportation, and disposal with minimal health and safety risks, is a great challenge endeavour for waste management businesses. In this respect, considerable technical knowledge and scientific and economic resources are needed to support the authorities' contingency plans. Therefore, it is wise to get the private business related to waste management involved in all plans' implementation stages to secure the supply chain and continuation of resources. This challenge has made many cities in the United States halted recycling programs fearing contaminated waste in recycling centres [17]. Some other major cities continue with their curbside pickup programs, while smaller municipalities have temporarily suspended their services [17]. Some of the hard-hit European nations have rolled back their waste disposal options. For example, Italy has banned infected residents from sorting their waste to avoid any risk of spreading the virus [17]. Also, the recycling industry business in some middle eastern countries, the Netherlands, and India reportedly been affected by the disruption in logistics due to the pandemic [18]. This disruption is why the waste businesses have been affected, which put forward a need for framework guidance to formulate the interrelation of the waste business and Governmental authorities to enable smooth management at any contingency. Panic induced throughout the pandemic has induced panic buying of necessary items, including food resulting in unnecessary stockpiling of perishable items. Hoarding food items with low shelf-life, 


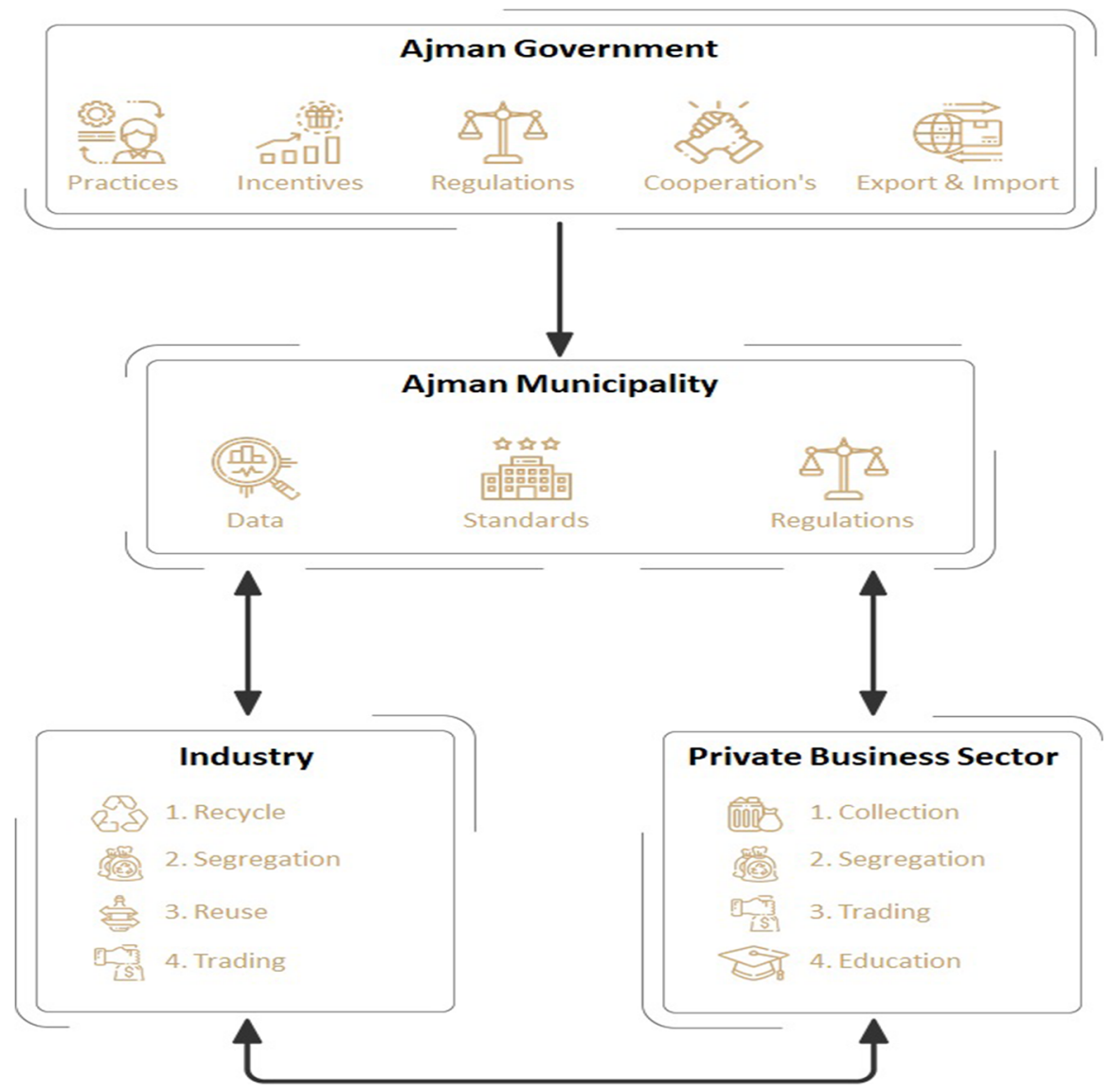

Fig. 13. Waste management sustainability model [Source: Author].

sometimes without cold storage facility, may increase waste generation. Also, lockdowns forced down has lead people to buy groceries online. This has resulted in a surge in packaging (paper and plastic) waste [19].

\subsection{Waste-business opportunities generated}

The management of waste in critical spaces requires that this is done sustainably to render embedded economic, social, and ecological rewards [20]. This requires that waste is first seen as an unavoidable product of industrial activity. Managing waste remains a formidable challenge that requires a strong alliance between private and public partners to find amicable solutions [21]. Empowering industries to manage waste has been argued as the most innovative and practical approach to waste management strategy set to get businesses to place sustainability at the top of their priority list $[22,23]$. It helps extend producer responsibility and creates a circular economy that retains the value of materials within the economy. Therefore, Renowned benefits exist for the Emirate of Ajman if industries are empowered to manage waste; these benefits go beyond the reduced level of waste sent to the landfills and incineration sites but have leveraged services to the economy as a whole. In Ajman, key initiatives have been introduced to make waste management attractive to private investors [24]. Nonetheless, to ensure that waste management is integrated into the same industry systems and structures that currently exist, these industries must be empowered to manage waste [25]. This analogy remains a central aspect of the Ajman Municipality Sustainability model presented in Figure 13.

AMPD has realized that to stand firm in facing any future pandemic, and as contingency acts, online management activities are to be designed and implement artificial intelligence applications to support domestic and business relationships.

Leading correlated indicators enhance the businesswaste relationship must look at recycling levels, landfillrates, and household waste percentage to support a waste management framework model [26]. In this respect, many European countries adapt waste indicators to reduce household waste, landfill rates and increase in waste recycling [26]. Waste associated business can reasonably be feasible and proved efficient when considering waste to energywhich is an appropriate solution that could be integratedinto the energy supply mix for a developing economy, considering the widespread perception that energy is anational security issue [27].

\section{Conclusion}

This paper highlighted the challenges that a pandemic such as COVID-19 can create on solid waste management. 
Comparison between 2019 and 2020 on the waste management amounts practices and policies were presented, which has drawn many conclusions. Change in the food, dynamics of plastic and biomedical waste generation during the same time has, however, stirred the woes of solid waste management. The virus-laden waste from indiscriminately discarded face masks, gloves, and other biomedical waste with the regular waste stream could cause heath risk to the sanitation workers. These facts have been explored regarding the Emirate of Ajman, where the most active authority that deals with waste management is the Ajman Municipality and Planning Department. The Municipality and Planning Department has dealt with many corresponding challenges, such as the waste from isolation areas and quarantine places were needed to be handled separately. In contrast, the regular waste stream can be taken as per the regular waste management provisions. The non-hazardous waste was considered hazardous in many cases to minimize the chances of contamination. Inevitably, plastic has increased as personal protection and healthcare items increased with the reduced recycling process to avoid its adverse effect. Household food waste has decreased during the pandemic due to the behavioural changes induced by socioeconomic contexts like rationing, conscious shopping, etc. The paper has explored many lessons learned from the pandemic and drew essential recommendations that could be put forward to the corresponding authority to consider when reviewing their contingency plans waste managements. The contingency planning step was summarised and presented to support plans for waste management. An essential remark is worth mentioning: the private business's need to support the Governmental efforts to deal with contingency and instance crises following a framework model for the business-focused interrelation between the Government's authorities. The business sectors engagement and enhancement must carefully be studied. The article highlighted various critical and practical factors embedded from the extensive practical experience gained throughout the pandemic. All together forms crisis-waste correlated practical framework that could well be adopted to deal with a similar pandemic and minimize the amount of waste and waste associated health and environmental issues.

\section{References}

1. N.R. Mosteanu, Intelligent foreign direct Investments to boost economic development-UAE case study, Bus. Manag. Rev. 10, 1-9 (2019)

2. TEN, Home: Living in the UAE: Ajman (Emirate and City), 2010. https://web.archive.org/web/20101006025407/http:// guide.theemiratesnetwork.com/living/ajman/

3. Ajman Department of Economic Development, Annual Economic Report Ajman 2015. Ajman DED, UAE, 2016

4. J. Alghazo, O. Ouda, F. Alanezi, M. Rehan, M.H. Salameh, A.S. Nizami, Potential of electronic waste recycling in Gulf
Cooperation Council states: an environmental and economic analysis, Environ. Sci. Pollut. Res. 26, 1-10 (2019)

5. J. Singh, R. Laurenti, R. Sinha, B. Frostell, Progress and challenges to the global waste management system, Waste Manag. Res. 32, 800-812 (2014)

6. Zoë Lenkiewicz, Waste and the Sustainable Development Goals - WasteAid. WasteAid, 2016. https://wasteaid.org/ waste-sustainable-development-goals

7. Sustainabledevelopment.un.org, Waste Management Sustainable Development Knowledge Platform, 2011. https:// sustainabledevelopment.un.org/index.php?page=view\&nr= $6 \&$ type $=504 \& \mathrm{me}$

8. Municipality \& Planning Department, Municipality and Planning Department discusses the integrated waste management projects and Ajman landfill with the Ministry of Climate Change and Environment| Ajman Municipality, 2020. https://www.am.gov.ae/media-center/press-news/munici pality-and-planning-department-discusses-the-integratedwaste-management-projects-and-ajman-landfill-with-theministry-of-climate-change-and-environment (accessed November 28, 2020)

9. Municipality \& Planning Department, City of Ajman Population and Waste management. Data requested by official communications, 2019

10. A. Bolukbas, G. Akinci, Solid waste composition and the properties of biodegradable fractions in Izmir City, Turkey: an investigation on the influencing factors, J. Environ. Health Sci. Eng. 16, 299-311 (2018)

11. L. Traven, I. Kegalj, I. Šebelja, Management of municipal solid waste in Croatia: analysis of current practices with performance benchmarking against other European Union member states, Waste Manag. Res. 36, 663-669 (2018)

12. OECD, Strategic foresight for the COVID-19 crisis and beyond: using futures thinking to design better public policies, OECD Publishing, 2020. http://www.oecd.org/ coronavirus / policy-responses/strategic-foresight-for-thecovid-19-crisis-and-beyond-using-futures-thinking-to-de sign-better-public-policies-c3448fa5/

13. UNEP \& IGES, Waste Management during the COVID-19 Pandemic From Response to Recovery, UN environment Programme and Institute for Global Environmental Strategies, Tsurumi-ku, Osaka - Japan, 2020

14. AMPD, Ajman Municipality and Planning Department, Contingency Plans For Hazardous Waste Management (Crises and Disasters), Planning Department. Private communications, 2020

15. AMPD. Waste Management Database (2019-2020). Requested through official communications. Ajman, UAE, 2021

16. Municipality \& Planning Department. Waste Management Developments. Report published by the Municipality, Ajman, UAE. Official communications and interviews, 2021

17. L. Kaufman, E. Chasan Bloomberg Green, Cities Wonder Whether Recycling Counts As Essential During the Virus, 2020. https://www.bloomberg.com/news/articles/2020-03$27 /$ cities-wonder-whether-recycling-counts-as-essential-dur ing-the-virus (accessed January 6, 2021)

18. BIR (Bureau of International Recycling), COVID-19: Update by BIR Member National Associations - The world 
Moves Tentatively Into Reopening Phase, 2020. https://bir. org/news-press/news / item/covid-19-update-by-bir-mem ber-national-associations-the-world-moves-tentatively-in to-reopening-phase (accessed January 6, 2021)

19. H.B. Sharma, K.R. Vanapalli, V.S. Cheela, V.P. Ranjan, A.K. Jaglan, B. Dubey, S. Goel, J. Bhattacharya, Challenges, opportunities, and innovations for effective solid waste management during and post COVID-19 pandemic, Resour. Conserv. Recycl. 162, 105052 (2020)

20. J.K. Seadon, Sustainable waste management systems, J. Clean. Prod. 18, 1639-1651 (2010)

21. J. Yeomans, Waste management using multicriteria population-based simulation-optimization algorithms, J. Waste Manag. Disposal 2, 1-8 (2019)

22. S. Cameron, How the resource and waste strategy can empower industry, 2019. https://sctimes.io/news/article/7/6476
23. J.L. Arranza, Empowering industries for zero waste economy, 2019. https://businessmirror.com.ph/2019/08/05/ empowering-industries-for-zero-waste-economy/

24. A. Abdullah, Private firms to manage Ajman's waste. Khaleej Times, 2017. https://www.khaleejtimes.com/na tion/ajman/private-firms-to-manage-ajmans-waste

25. N. Ferronato, V. Torretta, Waste mismanagement in developing countries: a review of global issues, Int. J. Environ. Res. Public Health 16, 1060 (2019)

26. T. Urmee, M. Anda, A. Chapman, M. Anisuzzaman, Green growth in cities: two Australian cases, Renew. Energy Environ. Sustain. 2, 43 (2017)

27. H.O. Iyamu, M. Anda, G. Ho, Socio-technical systems analysis of waste to energy from municipal solid waste in developing economies: a case for Nigeria, Renew. Energy Environ. Sustain. 2, 21 (2017)

Cite this article as: Khaled Mueen Alhosani, Pouria Liravi, COVID-19 impact on waste management - business opportunity

Emirate of Ajman - UAE, Renew. Energy Environ. Sustain. 6, 9 (2021) 